\title{
O lugar da cultura escrita nos documentos legais e oficiais da educação infantil: e os meninos e as meninas carregam letras na peneira
}

The place of written culture in legal and official documents of early childhood education: the boys and girls carry letters in the sieve

\section{El lugar de la cultura escrita en los documentos legales y oficiales de la educación infantil: los niños y las niñas cargan letras en el criba}

Regina Aparecida Marques de Souza ${ }^{1}$

Priscila Souza Damazio Piol ${ }^{2}$

DOI: http://dx.doi.org/10.20435/serie-estudos.v23i49.1145

\begin{abstract}
Resumo: O presente artigo é um recorte de uma pesquisa que iniciamos no ano de 2013 e deu origem à pesquisa de mestrado das autoras (orientadora e mestranda). O objetivo aqui é discutir o lugar ocupado pela cultura escrita nos documentos legais e oficiais na educação infantil, o que demanda estudos e reflexões de parte da prática docente. O estudo foi subsidiado pela Teoria Histórico-Cultural, tendo como um de seus principais representantes Lev Semionovich Vigotski. A metodologia de pesquisa insere-se na perspectiva qualitativa, em perspectiva bibliográfica e documental, tendo como foco as análises e reflexões sobre as concepções de cultura escrita, alfabetização, criança e infância, articuladas com a concepção de educação infantil brasileira. 0 estudo aponta caminhos para pensar a cultura escrita no contexto da educação infantil, mas com práticas e ações voltadas à infância, à criança e à situação social de seu desenvolvimento através da formação da capacidade de ler e escrever textos, mas com a preocupação em garantir à criança o direito a uma educação de qualidade e gratuita, tendo os documentos oficiais e legais como suporte para a organização do trabalho docente.
\end{abstract}

Palavras-chave: cultura escrita; infância; teoria histórico-cultural.

Abstract: The present article is a cut of a research that we started in the year 2013 and gave rise to the masters research of the authors (teacher and master). The objective here is to discuss the

\footnotetext{
${ }^{1}$ Universidade Federal de Mato Grosso do Sul, Três Lagoas, Mato Grosso do Sul, Brasil.

2 Secretaria Municipal de Educação, Campo Grande, Mato Grosso do Sul, Brasil.
} 
place occupied by written culture in legal and official documents in early childhood education, which demands studies and reflections from the teaching practice. The study was subsidized by Historical-Cultural Theory, having as one of its main representatives Lev Semionovich Vigotski. The research methodology is based on a qualitative perspective, in bibliographical and documentary perspective, focusing on the analyzes and reflections on the conceptions of written culture, literacy, children and childhood, articulated with the conception of Brazilian children's education. The study points out ways to think about written culture in the context of children's education, but with practices and actions aimed at children, the child and the social situation of their development through the formation of the ability to read and write texts, but with the concern to ensure to the child the right to a quality and free education, having the official and legal documents as support for the organization of the teaching work.

Keywords: written culture; childhood; historical-cultural theory.

Resumen: El presente artículo es un recorte de una investigación que iniciamos en el año 2013 y dio origen a la investigación de maestría de las autoras (orientadora y mestranda). El objetivo aquí es discutir el lugar ocupado por la cultura escrita en los documentos legales y oficiales en la educación infantil, lo que demanda estudios y reflexiones de parte de la práctica docente. El estudio fue subsidiado por la Teoría Histórico-Cultural, teniendo como uno de sus principales representantes Lev Semionovich Vigotski. La metodología de investigación se inserta en la perspectiva cualitativa, en perspectiva bibliográfica y documental, teniendo como foco los análisis y reflexiones sobre las concepciones de cultura escrita, alfabetización, niño e infancia, articuladas con la concepción de educación infantil brasileña. El estudio apunta caminos para pensar la cultura escrita en el contexto de la educación infantil, pero con prácticas y acciones dirigidas a la infancia, al niño ya la situación social de su desarrollo a través de la formación de la capacidad de leer y escribir textos, pero con la preocupación por garantizar al niño el derecho a una educación de calidad y gratuita, teniendo los documentos oficiales y legales como soporte para la organización del trabajo docente.

Palabras clave: cultura escrita; teoría histórico-cultural.

\section{PARA INÍCIO DE CONVERSA...}

Com o tempo, descobriu que escrever seria o mesmo que carregar água na peneira. No escrever, o menino viu que era capaz de ser noviça, monge ou mendigo ao mesmo tempo. O menino aprendeu a usar as palavras. Viu que podia fazer peraltagens com as palavras. E começou a fazer peraltagens. (Manoel de Barros, 2011).

Com a poesia de Manoel de Barros, iniciamos nosso artigo que tem como objetivo discutir o lugar da cultura escrita nos documentos legais e oficiais da educação infantil, articulados a nossos estudos sobre a Teoria Histórico-Cultural, ressaltando algumas concepções e alguns conceitos que nos auxiliaram na apropriação de uma concepção sobre educação infantil crítica e de qualidade, espe- 
cialmente na função de professoras, que somos, tanto em educação superior, como na Coordenadoria da Educação Infantil, situação profissional das autoras do artigo.

Pensar no menino que carrega água na peneira é pensar nas crianças que estão na educação infantil e que precisam carregar não só água, mas letras, muitas vezes letras do alfabeto que ficam expostas nas salas de atividades, em sua maioria em ordem alfabética, acima do quadro de giz e bem fora do alcance das crianças, que poderiam aproveitar para brincar, jogar, criar. Para elas, porém, o alfabeto é um objeto apenas para ser carregado na peneira, sem significado, sem sentido para a função que poderá ter num futuro dia a dia das crianças.

Assim, destacamos que apresentar como subsídio teórico da abordagem Histórico-Cultural é termos consciência de que tal teoria concebe, de acordo com Mello (2007, p. 86), "o ser humano e sua humanidade como produtos da história, criada pelos próprios seres humanos ao longo da história", e que isto nos remete a uma concepção de ser humano a partir de sua história, como produto da cultura que vem se desenvolvendo na articulação de conhecimentos criados desde gerações anteriores, que vão se adequando às necessidades, ao significado e ao sentido de cada um. Faz-se aqui necessário organizar os referenciais legais e oficiais para os encaminhamentos da educação, em especial a infantil, e pensar as práticas docentes neles propostas.

É dentro dessa concepção que apresentamos nossa discussão sobre os documentos legais e oficiais sobre educação infantil nos últimos vinte anos, a partir da promulgação da Lei de Diretrizes e Bases da Educação Nacional (LDBEN) n. 9.394, em 1996, que coloca a educação infantil como primeira etapa da educação básica, que nos propõe um novo olhar sobre a educação de nossas crianças menores de seis anos.

Organizamos o artigo num texto que dialoga consigo mesmo na perspectiva de trazer à discussão os conceitos de criança, infância e cultura escrita a partir do estudo nos documentos legais e oficiais na tentativa de responder à questão: alfabetiza-se ou não na educação infantil? Ao finalizar essa conversa, permitimo-nos oferecer nossa opinião sobre a questão, articulada ao nosso suporte teórico, legal e oficial.

Em nossa tentativa de propor que o que as crianças podem e devem carregar é água na peneira, e não letras, partimos para a diálogo... 


\section{2 "E OS MENINOS E MENINAS CARREGAM LETRAS NA PENEIRA..." 0 LUGAR DA CULTURA ESCRITA NA EDUCAÇÃO DAS CRIANÇAS PEQUENAS}

Propomo-nos a compreender que concepções de criança, infância e linguagem/cultura escrita se depreendem dos documentos legais e oficiais da educação infantil, no intuito de verificar se nessa etapa da educação básica ensinamos e se as crianças aprendem a ler e a escrever. A necessidade de tal investigação decorre do fato de que são esses documentos os principais norteadores do trabalho pedagógico em educação infantil. Os professores, muitas vezes, incorporam os discursos contidos nesses textos sem repassá-los às práticas neles sugeridas. São estes, entre outros, os materiais consultados para a elaboração do planejamento pedagógico do professor e para a reflexão sobre a constituição legal da educação infantil.

Segue uma breve descrição dos documentos consultados para o desenvolvimento do presente artigo, organizados por ordem cronológica e classificados em documento oficial ou legal. Entendemos por documentos oficiais aqueles:

[...] cujas informações são relevantes para as áreas para as quais foram propostos; entretanto não são mandatórios, são documentos elaborados para indicar o posicionamento de determinado órgão de consulta com a finalidade primeira de orientar e de fundamentar, em algumas vezes, documentos legais. (TEIXEIRA, 2014, p. 55).

Os documentos de caráter legal, por sua vez, têm força de lei e são elaborados com o objetivo de definir direitos e deveres sociais. Assim, temos:

1. a Lei de Diretrizes e Bases da Educação Nacional (LDBEN)n. 9.394, de 20 de dezembro de 1996 (documento legal);

2. os Referenciais Curriculares Nacionais para a Educação Infantil (RCNEI) (três volumes), de 1998-Documento oficial;

3. o Parecer CEB n. 22, de 17 de dezembro de 1998- Diretrizes Curriculares Nacionais para a Educação Infantil (documento legal);

4. a Resolução CEB n. 1, de 7 de abril de 1999-Instituir as Diretrizes Curriculares Nacionais para a Educação Infantil (documento legal);

5. os Parâmetros Nacionais de Qualidade para a Educação Infantil de 2006 (documento oficial);

6. a Política Nacional de Educação Infantil: pelo direito das crianças de zero a seis anos à Educação, de 2006 (documento oficial); 
7. os critérios para um Atendimento em Creches que Respeite os Direitos Fundamentais das Crianças, de 2009 (documento oficial);

8. os Indicadores da Qualidade na Educação Infantil, de 2009 (documento oficial);

9. a Política de Educação Infantil no Brasil: Relatório de Avaliação, de 2009 (documento oficial);

10. a Emenda Constitucional n. 59, de 11 de novembro de 2009 (documento legal);

11. a Resolução CNE/CEB n. 5, Diretrizes Curriculares Nacionais para a Educação Infantil, de 17 de dezembro de 2009 (documento legal).

Partimos da LDBEN n. 9.394/1996, que determina a obrigatoriedade da matrícula apenas no ensino fundamental. O documento deixa claro que também essa etapa da educação básica é prioridade para a atuação dos municípios, aos quais incumbe:

$V$ - oferecer a educação infantil em creches e pré-escolas, e, com prioridade, o ensino fundamental, permitida a atuação em outros níveis de ensino somente quando estiverem atendidas plenamente as necessidades de sua área de competência e com recursos acima dos percentuais mínimos vinculados pela Constituição Federal à manutenção e desenvolvimento do ensino. (BRASIL, 1996, p. 14).

Consideramos a LDBEN/1996 uma conquista para a educação infantil no que diz respeito à sua inclusão na educação básica, pois o atendimento às crianças pequenas passa a ser regulamentado no âmbito da educação. Percebemos, no entanto, que a seção que trata da educação das crianças pequenas é breve (três artigos), ressaltando que a finalidade da educação infantil é "o desenvolvimento integral da criança até seis anos de idade, em seus aspectos físico, psicológico, intelectual e social, complementando a ação da família e da comunidade" (BRASIL, 1996, p. 22). O documento decide ainda a abertura de creches para crianças de até três anos e de pré-escolas para as da faixa etária de quatro a seis.

O último artigo da seção voltado à educação infantil diz que a avaliação não tem por objetivo a promoção ao ensino fundamental, e que deverá ocorrer por meio de acompanhamento e registro do desenvolvimento da criança.

O documento completou duas décadas de existência; ainda hoje, entretanto, encontramos professores/as com discursos que defendem que a criança "preci- 
sa" chegar ao ensino fundamental alfabetizada. Assim, questionamos: Para os documentos legais e oficiais, qual o lugar da cultura escrita na educação infantil?

Para responder a tal questão, partimos para a pesquisa e a compreensão de outros documentos que trazem a educação infantil como referência, entre eles o Referencial Curricular Nacional para a Educação Infantil (RCNEI), um dos primeiros documentos oficiais, de 1998, no momento da troca da representante da Coordenação Geral de Educação Infantil (Coedi). Angela Barreto fora substituída por Gisela Wajskop, gerando polêmicas sobre a não continuidade do trabalho desenvolvido pela primeira. Pesquisadores/as da educação infantil se questionaram sobre o descompromisso do documento com a realidade brasileira nas propostas de pedagógicas, pois:

[...] à medida que a leitura do referencial vai nos remetendo àquela infância desejada, rica de estímulos, pertinente quanto à adequação do vínculo do educador com a criança, e vai nos seduzindo, transportando, remetendo para criança idealizada, ele nos afasta da realidade da maioria das creches brasileira, desconhecendo ou ocultando parte dos conhecimentos anteriormente sistematizados e divulgados. (FARIA; PALHARES, 2007, p. 10).

Tais pesquisadores/as indicam, portanto, a necessidade de um olhar crítico e questionador durante a leitura dos referenciais, assim como, acreditamos, devemos fazer com todo material escrito.

Em nossa opinião, um documento que se proponha a oferecer uma referência sobre currículo deve considerar todos os aspectos relacionados ao fazer pedagógico; dentre eles, a realidade do espaço físico e as condições de trabalho dos professores. A despeito dessas e outras críticas, o RCNEI é um marco para os estudos sobre a apropriação da linguagem oral e escrita pela criança no Brasil, pois é o primeiro documento legal a tratar diretamente do assunto, trazendo, em seu terceiro volume, um tópico específico para o debate.

O documento (RCNEI) resulta da discussão entre professores e profissionais dedicados à educação infantil, seja na experiência prática, seja no âmbito das reflexões acadêmicas; porém, nem sempre o conjunto de documentos deixa clara sua posição a respeito de alguns conceitos. Nos debates sobre concepções de criança, formas de cuidado e cultura escrita, por exemplo, o texto faz várias considerações sobre práticas em vigência e aponta, de forma branda (quando o faz), a que entende como a mais indicada/aconselhada. 
Compreendemos, face à realidade dinâmica do trabalho, que toda proposta pedagógica para a educação infantil precisa ser flexível; entretanto acreditamos que o documento deveria trazer uma posição mais firme com relação a conceitos imprescindíveis ao trabalho com crianças pequenas.

No volume um, em um trecho que trata de criança e aprendizagem, uma nota de rodapé indica que os trabalhos de Vigotski, Piaget e Wallon "[...] apresentam tanto convergências como divergências" e "têm influenciado marcadamente o campo da educação" (BRASIL, 1998b, p. 22). Reconhecemos o legado e as contribuições dos três pensadores citados para pensar a criança; todavia acreditamos que "juntar" seus respectivos estudos para embasar uma prática pedagógica pode causar certa dificuldade, e até confusão, pois suas teorias são diferentes, e até divergentes. É certo que Vigotski e Wallon dialogam em suas bases teóricas; no entanto Piaget diverge em vários aspectos, sobretudo nas concepções de aprendizagem e desenvolvimento. Por fugir ao escopo desta pesquisa, não vamos enfatizar aqui tal discussão.

Uma das críticas ao documento (RCNEI) é justamente a de não ter exposto explicitamente, à época de sua publicação, as referências teóricas que o ancoram. No livro Educação infantil pós-LDB: rumos e desafios, organizado pelas pesquisadoras Ana Lúcia Goulart de Faria e Marina Silveira Palhares, além das críticas anteriores, é apontada a falta de posicionamento teórico: “[...] por vezes misturam referências que são antagônicas em suas origens, não faz avançar a produção do conhecimento" (FARIA; PALHARES, 2007, p. 14-5).

Apesar da falta de transparência no documento a respeito da definição de algumas compreensões, fazemos uma reflexão sobre os três volumes, em busca da proposta de trabalho do RCNEI para a cultura escrita na educação infantil e de uma análise das concepções específicas.

No primeiro volume, o documento reconhece o conceito de criança como historicamente construído e que varia de acordo com a classe social ou grupo cultural:

A criança, como todo ser humano, é um sujeito social e histórico e faz parte de uma organização familiar que está inserida em uma sociedade, com uma determinada cultura, em um determinado momento histórico. É profundamente marcada pelo meio social em que se desenvolve, mas também o marca. A criança tem na família, biológica ou não, um ponto de referência fundamental, apesar da multiplicidade de interações sociais que estabelece com outras instituições sociais. (BRASIL, 1998b, p. 21). 
A partir de tal compreensão de criança, cabe ao professor valorizar os conhecimentos que ela detém e respeitar a cultura que comunga com as pessoas com as quais convive fora da instituição, entendendo que temos diversos tipos de crianças que vivem em diferentes contextos sociais e culturais.

O documento revela a intenção de superar o caráter assistencialista, historicamente presente nas instituições de educação infantil, afirmando que tal tarefa envolve "[...] assumir as especificidades da educação infantil e rever concepções sobre a infância, as relações entre classes sociais, as responsabilidades da sociedade e o papel do Estado diante das crianças pequenas" (BRASIL, 1998b, p. 17).

Assim, refletindo sobre o sentido de assumir as especificidades da primeira etapa da educação básica, somos de parecer que os profissionais que trabalham com crianças pequenas devem ter claros os cuidados por elas requeridos, sem abrir mão do direito adquirido à educação. Para desenvolver uma prática que reconheça tais especificidades, esses profissionais necessitam das devidas condições de trabalho, cabendo ao Estado garanti-las.

A criança pequena precisa ser cuidada e auxiliada. Se auxiliada por um sujeito mais experiente, aprende a fazer autonomamente. Por exemplo: ela não sabe lavar-se ou trocar-se sozinha; no entanto, nos momentos de cuidado, pode ter a oportunidade de descobrir o próprio corpo e aprender a estabelecer domínio sobre ele, assim como acontece no decorrer de sua vida na apropriação de novos conhecimentos. Ressaltamos que estes aprendizados precisam ocorrer numa perspectiva desenvolvente, como afirma Mello, apoiada nos escritos de Davidov (1930-1998):

Falar em educação desenvolvente [...] implica afirmar a compreensão de que a educação é responsável por formar e desenvolver nas novas gerações as funções psicológicas superiores - como o pensamento, a fala, a imaginação, a atenção e a memória voluntárias, o autocontrole da vontade - que constituem a consciência humana. Em outras palavras, pela educação formamos as qualidades humanas que não nascem com as crianças e precisam ser construídas ao longo da vida. (MELLO, 2012, p. 75).

Tais qualidades começam a ser construídas desde os primeiros anos de vida da criança, razão por que as relações de cuidado não podem perder de vista o aspecto educativo e formativo do indivíduo. 
É na troca com o outro que a criança se desenvolve; daí a importância dos momentos de socialização e interação com os diferentes sujeitos envolvidos no processo, tanto adultos quanto crianças. Tais momentos precisam ser garantidos cotidianamente nas instituições de educação infantil. A brincadeira pode ser um elemento impulsionador para essas trocas, especialmente na relação da criança com seus pares.

De acordo com Vigotski, por meio das brincadeiras a criança vivencia papéis, adota condutas e regras, articuladas a uma determinada personagem ou figura próxima que ela quer imitar. Assim, a brincadeira é uma linguagem lúdica que pode ajudar a criança a superar dificuldades e a desenvolver sua imaginação e criatividade. Mais que isso, segundo Vygotsky (2008, p. 24), ela "[...] é a linha principal do desenvolvimento na idade pré-escolar". Vemos, na afirmação do autor, a importância da brincadeira para a aprendizagem e o desenvolvimento da criança; no entanto, é importante enfatizar o perigo de didatizar a brincadeira, pois, por meio dela, a criança pode aprender e desenvolver-se. É massacrante, todavia, que professores façam da brincadeira apenas um recurso para o ensino de conteúdos.

O professor precisa ter responsabilidade ao conduzir o trabalho pedagógico, pois seu papel é aproximar as crianças de situações significativas que promovam boas vivências e aprendizados. Na educação infantil, os profissionais precisam aliar, sem separar, momentos de cuidado e aprendizado: cuidar enquanto educam e educar enquanto cuidam. Quando falamos em cuidar, não nos referimos somente aos cuidados físicos, relacionados à higiene, mas também ao respeito à infância e à valorização pessoal de cada indivíduo.

Valorizar a criança implica considerar os conhecimentos e experiências que ela possui e compartilha em seu meio social e cultural, pois:

[...] o meio desempenha no desenvolvimento da criança, no que se refere ao desenvolvimento da personalidade e de suas características específicas ao homem, o papel de uma fonte de desenvolvimento, ou seja, o meio, nesse caso, desempenha o papel não de circunstância, mas de fonte de desenvolvimento. (VIGOTSKI, 2010, p. 695).

A criança possui uma história que tem início muito antes de seu ingresso na instituição educativa. Quando tratamos do trabalho com a cultura escrita na educação infantil, este precisa ser o ponto de partida para o professor desenvolver 
uma ação significativa para a criança. Sim, para a criança. Ela é protagonista do fazer pedagógico na primeira etapa da educação básica e nela deve ser centrado o empenho do professor, que também assume o protagonismo da ação de ensinar e aprender articulados pelo protagonismo da cultura, que medeia a aprendizagem/ ensino dos outros dois protagonistas. Assim, pela Teoria Histórico-Cultural, temos um triplo protagonismo, não o delegando exclusivamente à criança, mas articulando entre os três uma ação consciente e capaz de aprender-ensinar-desenvolver em conjunto, especialmente no trabalho com a cultura escrita na educação.

A cultura escrita não é apresentada à criança apenas pelo professor no contexto da instituição educativa; seu contato com ela se dá nas relações cotidianas. A compreensão que o RCNEI traz é que:

A prática educativa deve buscar situações de aprendizagens que reproduzam contextos cotidianos nos quais, por exemplo, escrever, contar, ler, desenhar, procurar uma informação etc. tenha uma função real. Isto é, escreve-se para guardar uma informação, para enviar uma mensagem, contam-se tampinhas para fazer uma coleção etc. (BRASIL, 1998b, p. 35).

Nessas situações do dia a dia, a criança aprende. Convive, por meio das ações de falar, escutar, ler e escrever (ou registrar), que compõem a rotina da educação infantil, com atitudes produtoras de texto e leitura e compreende que tais conhecimentos podem ser utilizados cotidianamente. Nesse sentido, a instituição educativa torna-se um espaço privilegiado para promover vivências significativas de relações com a cultura escrita, proporcionando à criança momentos de comunicação e expressão com os mais diversos meios portadores de textos e uso social da linguagem escrita.

O volume três do RCNEl traz uma reflexão sobre o aprendizado de uma língua, afirmando que tal processo não demanda somente aprender palavras, "mas também os seus significados culturais e, com eles, os modos pelos quais as pessoas do seu meio sociocultural entendem, interpretam e representam a realidade" (BRASIL, 1998c, p. 117). A Teoria Histórico-Cultural destaca:

[...] quando lemos, não nos interessa o som das palavras escritas, mas o real - as ideias, a informação, os sentimentos - a que elas se referem. [...] ainda que a escrita seja uma representação de segunda ordem (referindo-se ao fato de que a escrita representa a fala, e a fala representa o mundo real), ela precisa se tornar uma representação de primeira ordem. (MELLO, 2012, p. 80). 
A tarefa de alfabetizar NÃO cabe à educação infantil, mas ao ensino fundamental, como podemos encontrar nos documentos oficiais e legais. Na primeira etapa da educação básica, é desejável que as crianças se relacionem com a linguagem escrita como uma produção cultural humana que esteja presente em seu dia a dia.

Os atos de falar, escutar, ler e escrever (ou registrar) não têm, muitas vezes, o espaço que merecem e precisam ter no cotidiano da educação infantil. Muitos professores engessam tais ações em sua rotina, sem oportunizar ou mesmo deixar as crianças à vontade para se expressar. Isto costuma ocorrer com os usos da linguagem oral. Muitas instituições permitem a fala espontânea da criança apenas durante a roda de conversa, sendo este o único momento em que ela pode falar e, algumas vezes, apenas sobre o assunto ou tema estabelecido pelo professor. A instituição educativa não pode ser um espaço em que apenas adultos sejam sujeitos de decisões; a criança também é um membro do/no grupo e faz parte da vida da instituição.

A escrita também está presente no dia a dia da educação infantil. Se a intenção do professor é formar crianças leitoras e produtoras de texto, cabe-Ihe, na condição de organizador, valorizá-la nas situações reais e cotidianas, tais como: quando presencia atos de leitura e escrita, como anotações corriqueiras de contatos telefônicos e bilhetes, leitura de recados, notícias, informações em catálogos de compras ou contação de histórias. Em situações como essas, as crianças começam a vivenciar a cultura escrita e compreendem sua função na sociedade.

O referencial deixa claro não ser proposta da primeira etapa da educação básica alfabetizar as crianças pequenas, como afirmamos anteriormente. $\mathrm{O}$ documento traz o entendimento de que o aprendizado da leitura e da escrita faz "parte de um longo processo ligado à participação em práticas sociais de leitura e escrita" (BRASIL, 1998c, p. 123). Em parte alguma do texto a alfabetização, ou seja, o processo de ensinar e aprender a ler e a escrever, é mencionada como tarefa da educação infantil; a tônica é que se deve pôr a criança em contato com a cultura escrita por meio de práticas cotidianas de leitura e escrita de forma prazerosa e significativa.

Encaminhando nossa pesquisa, chegamos à primeira versão das Diretrizes Curriculares Nacionais para a Educação Infantil/DCNEI, elaborada pelo Parecer CEB n. 22, de dezembro de 1998, que trazia, nos objetivos, a intenção de valorizar: 
[...] ainda mais a Educação Infantil e sua pertinência como momento e lugar de transição entre a vida familiar e a Escola, encerrando a era das "Classes de Alfabetização", desnecessárias e desaconselháveis, uma vez que se considere que o processo de interpretação e produção de textos, de compreensão de quantidades e operações de cálculo, assim como de situar-se em relação aos meios sociais e naturais, relacionando-se com eles, não acontece nem se cristaliza em apenas um ano letivo. (BRASIL, 1998a, p. 9).

Como podemos verificar, há quase duas décadas a alfabetização na educação infantil já era definida como desaconselhável; ainda hoje, no entanto, percebemos práticas convictas da importância de a criança ingressar no ensino fundamental sabendo ler e escrever. Nossos estudos nos levam a compreender que a cultura escrita pode e deve ser vivenciada desde os primeiros anos de vida, mas de forma que a criança perceba essa forma de linguagem como meio de cultura. Sabemos que tal processo abre a ela uma possibilidade deformar a atitude leitora e produtora de texto na educação infantil, como afirma Mello (2012).

Instituídas e publicadas pela Resolução CEB n. 1, em 7 de abril de 1999, as Diretrizes Curriculares Nacionais para a Educação Infantil estão organizadas em poucas páginas e apontam práticas pedagógicas a serem observadas na organização do trabalho com crianças.

Apesar de não tratar especificamente da língua escrita, as DCNEI de 1999 recomendam que as áreas de conhecimento estejam relacionadas aos aspectos da vida da criança, ou seja, dialogando com nossa compreensão, pautada na Teoria Histórico-Cultural, entendemos que devem fazer sentido em sua realidade.

Destacamos não encontrar no texto, tanto do parecer n. 22/1998, quanto nas DCNEI/1999, que a alfabetização não é função da educação infantil. Quer dizer, não temos indicação alguma de alfabetização, ação de ensinar e aprender a ler e a escrever, mas temos que, no trabalho intencional, organizado pelo professor, as várias linguagens devem ser privilegiadas nas atividades do dia a dia na educação das crianças pequenas.

Em 2006, foram publicados os Parâmetros Nacionais de Qualidade para a Educação Infantil (PNQEI), que buscam cumprir a determinação do PNE/2001 quanto à garantia de qualidade na primeira etapa da educação básica. Tal documento oficial está organizado em dois volumes e se propõe a servir de referência à organização e ao funcionamento das instituições de educação infantil (BRASIL, 2006a). 
Os parâmetros revelam uma visão de criança como um "sujeito social e histórico que está inserido em uma sociedade na qual partilha de uma determinada cultura" (BRASIL, 2006a, p. 13). Com isso, as especificidades da criança e suas possibilidades sustentam-se, inclusive,na compreensão de Eloísa Rocha:

Enquanto a escola tem como sujeito o aluno, e como objeto fundamental o ensino nas diferentes áreas através da aula, a creche e a pré-escola têm como objeto as relações educativas travadas num espaço de convívio coletivo que tem como sujeito a criança de 0 até 6 anos de idade. (ROCHA apud BRASIL, 2006a, p. 17).

Tal citação revela-nos o entendimento de que o sujeito da educação infantil possui particularidades que precisam ser levadas em conta no desenvolvimento do trabalho do professor: esse sujeito deve ser tratado como criança, e não como aluno. Apesar de não encontrarmos discussões específicas sobre a cultura escrita (apenas a orientação do trabalho com as várias linguagens), a citação deixa transparecer a concepção implícita no documento: a instituição de educação infantil diferencia-se do ensino fundamental no que diz respeito aos objetivos, ao trabalho pedagógico e à condução das propostas.

Reforçamos aqui nossa compreensão de que a infância não se encerra aos seis anos, ou com a saída da educação infantil e que os anos iniciais do ensino fundamental devem garantir-Ihe vivências que contemplem a infância em suas várias peneiras. As práticas voltadas à cultura escrita precisam ter, como objetivo, proporcionar à criança o contato com os usos e funções reais da cultura escrita, a partir de sua compreensão como produto cultural humano, carregado de sentido e significado, e não apenas as letras do alfabeto.

Os parâmetros são um documento que contém referências de qualidade para a educação infantil a serem utilizadas pelos sistemas educacionais-creches, pré-escolas e centros de educação infantil-, com vistas a promover a igualdade de oportunidades educacionais, levando em conta as diferenças, as diversidades e desigualdades de nosso imenso território e das muitas culturas nele presentes. Encontramos, no referido documento, indicações de uma organização de atividades que contemplam as várias linguagens de um conjunto de ações do dia a dia das crianças na instituição. A linguagem oral e escrita é citada dentro do contexto maior das várias linguagens; em nenhuma parte do documento encontramos indicações para o ensino da leitura e da escrita de forma siste- 
mática e mecânica. Assim, não há espaço para a alfabetização das crianças na educação infantil.

Ainda em 2006, o Ministério da Educação publica a Política Nacional de Educação Infantil: pelo direito das crianças de zero a seis anos à Educação, apresentando diretrizes, objetivos, metas e estratégias para a educação infantil. Dentre os objetivos, está a garantia de acesso das crianças à primeira etapa da educação básica, oferecendo atendimento e infraestrutura de qualidade e, também, a garantia de recursos financeiros para a manutenção e desenvolvimento das instituições.

Tal documento preconizou a construção coletiva das políticas públicas para a educação. Nele encontramos:

[...] é imprescindível garantir que as salas continuem disponíveis para a Educação Infantil, não sendo utilizadas para o Ensino Fundamental e tampouco transformadas em salas de alfabetização. A inclusão das crianças de 6 anos no Ensino Fundamental, no entanto, não pode ser efetivada sem que sejam consideradas as especificidades da faixa etária, bem como a necessidade primordial de articulação entre essas duas etapas da Educação Básica. (BRASIL, 2006b, p. 6).

Como podemos comprovar, o documento reforça o princípio segundo o qual a tarefa de alfabetizar não é da educação infantil. Mesmo para o ensino fundamental, momento em que a criança passa pelo processo de alfabetização sistemática, o documento prevê que sejam consideradas as especificidades da infância, respeitando-a e considerando as potencialidades dos sujeitos envolvidos. Essa discussão se amplia com a Lei n. 11.274, de 6 de fevereiro de 2006, que institui o ensino fundamental de nove anos, com a inclusão das crianças de seis anos de idade.

Em 2009, é publicada a segunda versão do documento Critérios para um Atendimento em Creches que Respeite os Direitos Fundamentais das Crianças. A primeira versão surgiu de um projeto de assessoria e formação de profissionais de Belo Horizonte, MG e foi discutida no 1 ㅇ Simpósio Nacional de Educação Infantil, passando a contar, ao final de 1994, com o apoio do MEC e colaboradores, para refletir sobre a nova versão do documento, de 2009.

Embora muitas definições ali contidas se apliquem também aos anos finais da educação infantil, o documento dedica-se a refletir sobre a qualidade da educação para as crianças de zero a três anos. A publicação divide-se em duas 
partes: a primeira, define critérios relativos à organização e ao funcionamento das instituições; a segunda, indica critérios sobre diretrizes, políticas, programas e financiamento das creches.

A creche que respeita a criança, segundo o documento, garante o direito à brincadeira, à atenção individual, ao contato com a natureza, à higiene e à saúde, ao desenvolvimento da curiosidade, à imaginação e à capacidade de expressão, ao movimento em espaços amplos, à proteção, ao afeto e à amizade, à expressão de sentimentos, a uma especial atenção durante seu período de adaptação à creche, ao desenvolvimento da identidade cultural, racial e religiosa (BRASIL, 2009a).

As reflexões levantadas por esse documento podem, e devem, avançar para outras faixas etárias. Acreditamos que os direitos apontados precisem ser garantidos a todas as crianças. São estas as vivências que os professores precisam garantir ao planejar suas propostas com as crianças da educação infantil. 0 documento não se detém a refletir sobre a cultura escrita; no entanto destacamos que o desenvolvimento do trabalho com a escrita deve considerar todos os direitos apontados.

Em 2009, são publicados também os Indicadores da Qualidade na Educação Infantil, elaborados pelo MEC em parceria com a Fundação Orsa, a União Nacional dos Dirigentes Municipais de Educação (Undime), o Fundo das Nações Unidas para a Infância (Unicef) e pesquisadores da educação para a infância. Os indicadores configuram-se como instrumento de autoavaliação para as instituições de educação infantil. De acordo com o documento:

As definições de qualidade dependem de muitos fatores: os valores nos quais as pessoas acreditam; as tradições de uma determinada cultura; os conhecimentos científicos sobre como as crianças aprendem e se desenvolvem; o contexto histórico, social e econômico no qual a escola se insere. No caso específico da educação infantil, a forma como a sociedade define os direitos da mulher e a responsabilidade coletiva pela educação das crianças pequenas também são fatores relevantes. (BRASIL, 2009b, p. 13).

Os referidos indicadores, como se pode verificar, reconhecem serem vários os fatores e contextos que interferem nas relações que a criança estabelece dentro e fora da instituição. Assim, os critérios para definir qualidade variam de acordo com a compreensão de diversos conceitos, conforme as condições sociais, 
históricas e culturais da sociedade da qual a instituição faz parte. Alguns aspectos importantes podem, no entanto, de acordo com o documento, ser considerados, tais como: o respeito aos direitos humanos fundamentais; o reconhecimento e a valorização das diferenças de gênero, étnico-raciais, religiosas, culturais e relativas a pessoas com deficiência; o respeito ao meio ambiente, o desenvolvimento de uma cultura de paz e a busca de relações humanas mais solidárias; a legislação educacional brasileira, bem como os conhecimentos científicos sobre desenvolvimento infantil, infância e práticas de cuidar e educar (BRASIL, 2009b).

Os indicadores de qualidade na educação infantil podem ser utilizados tanto pelos profissionais da instituição quanto pela comunidade, com o intuito de refletir sobre as melhorias necessárias a cada instituição, de acordo com seu contexto. A dimensão que discute experiências com a linguagem escrita é a segunda. $O$ indicador 2.5 traz para o leitor uma reflexão sobre a cultura escrita quando destaca maneiras de se trabalhar com as linguagens oral e escrita.

As experiências descritas no indicador 2.5 remetem às experiências com a cultura escrita que consideramos essenciais na educação infantil: o contato com portadores de texto; a contação diária de histórias; o contato com a escrita, entre outras. É assim que, em nossa percepção, o trabalho pedagógico deve acontecer com as crianças pequenas no que diz respeito à cultura escrita. Em nenhum momento, o texto cita a palavra "alfabetização" ou indica o ensino sistematizado do ler e do escrever, o que reforça nossa compreensão de que a educação infantil precisa promover vivências que fomentem a formação da atitude leitora e produtora de textos na criança.

Ainda no ano de 2009, o MEC publica a Política de Educação Infantil no Brasil: Relatório de Avaliação, que resulta do projeto de Avaliação das Políticas Públicas para a Primeira Infância, desenvolvido por uma parceria da Organização das Nações Unidas para a Educação, a Ciência e a Cultura (Unesco) e a Organização para Cooperação e Desenvolvimento Econômico (OCDE). No Brasil, a avaliação:

[...] foi subsidiada em sua metodologia por estudos específicos, elaborados por especialistas brasileiros, a respeito de quatro temáticas fundamentais sobre as políticas e serviços de educação e cuidado com a primeira infância: competências das instâncias governamentais, indicadores de acesso e condições de oferta, qualidade e financiamento. (BRASIL, 2009d, p. 7). 
O documento, dividido em três partes, aponta problemas estruturais na educação infantil brasileira. A primeira parte apresenta a tradução para a língua portuguesa do Relatório de Avaliação da Política de Cuidado e Educação da Primeira Infância no Brasil, publicado em 2007, em língua inglesa, no site da Unesco. A segunda parte traz os textos que fundamentaram as análises; a terceira, atualiza o quadro da educação infantil no Brasil, com informações sobre leis e programas para a educação de crianças. Segundo a publicação:

Um bom programa de educação pré-primária prepara a criança para a escolarização formal como parte de um desenvolvimento holístico. A ênfase deve ser colocada num desenvolvimento equilibrado, não apenas no aspecto cognitivo, mas também nos aspectos social, emocional, comunicativo e físico. O sucesso na escola depende não apenas da capacidade de ler, escrever e contar, mas também, e mais importante, da disposição para aprender e da capacidade de se comunicar e se adaptar ao ambiente social da vida escolar. Se a educação infantil é o pilar da aprendizagem ao longo da vida inteira, isso não acontece ajudando a criança a adquirir habilidades específicas de aprendizado, mas ajudando-a a se tornar uma pessoa integral. Nos programas de educação infantil, brincar e interagir são mais importantes do que estudo e instrução. (BRASIL, 2009d, p. 53).

Em nosso entendimento, o uso do verbo "preparar", aplicado à "criança", seria inadequado, uma vez que consideramos a criança um ser em desenvolvimento, embora capaz e ativa no processo de aprendizagem. Na educação infantil, mais importante que estudar e ser instruído é vivenciar situações propiciadas pelas brincadeiras e interações. Segundo Vigotski (2010, p. 683-4):

A vivência de uma situação qualquer, a vivência de um componente qualquer do meio determina qual influência essa situação ou esse meio exercerá na criança. Dessa forma, não é esse ou aquele elemento tomado independentemente da criança, mas, sim, o elemento interpretado pela vivência da criança que pode determinar sua influência no decorrer de seu desenvolvimento futuro.

Dessa forma, as relações estabelecidas com o meio dependem diretamente da vivência de cada criança; não só sobre como experimenta as diversas situações da instituição, mas também sobre como é tocada interiormente por essas vivências. Uma discussão positiva, levantada pelo documento, é sobre o desenvolvimento holístico, pois a criança necessita ser compreendida de maneira integral 
e como pertencente a uma sociedade que ultrapassa os muros da instituição educativa. Assim, precisa ter garantidas vivências que Ihe permitam relacionar as experiências da instituição com sua vida cotidiana.

Em 2009, são reformuladas as Diretrizes Curriculares Nacionais para a Educação Infantil pelo Parecer CNE/CEB n. 20. Publicadas no ano seguinte, surgem estruturadas em tópicos mais específicos que as DCNEI anteriores. O documento apresenta uma concepção de educação infantil que prevê sujeitos desfrutando de direitos civis, humanos e sociais, bem como de igualdade de oportunidades e vivência da infância num espaço de práticas de cuidado e educação que possibilitem a interação das crianças entre elas e com os/as adultos/as (BRASIL, 2009c).

Revelam, ainda, a compreensão de criança como:

[...] sujeito histórico e de direitos que se desenvolve nas interações, relações e práticas cotidianas a ela disponibilizadas e por ela estabelecidas com adultos e crianças de diferentes idades nos grupos e contextos culturais nos quais se insere. Nessas condições ela faz amizades, brinca com água ou terra, faz-de-conta, deseja, aprende, observa, conversa, experimenta, questiona, constrói sentidos sobre o mundo e suas identidades pessoal e coletiva, produzindo cultura. (BRASIL, 2009c, p. 6-7).

Assim, a criança é concebida como um ser completo e em constante desenvolvimento, que necessita ter garantidos os direitos à proteção, à saúde, à liberdade e à brincadeira. Este último direito, ao lado da interação, é um dos eixos norteadores do trabalho com crianças pequenas.

As diretrizes, como documento oficial e mandatório, reafirmam concepções já apontadas pelo RCNEI, como: o entendimento do cuidado como indissociável das práticas educativas; o reconhecimento da singularidade da criança de acordo com as especificidades etárias; o dever das instituições de educação infantil de promoverem experiências com as diferentes linguagem e formas de expressão.

Um ponto importante discutido pelas DCNEl é a articulação da educação infantil com o ensino fundamental:

Na transição para o Ensino Fundamental, a proposta pedagógica deve prever formas para garantir a continuidade no processo de aprendizagem e desenvolvimento das crianças, respeitando as especificidades etárias, sem antecipação de conteúdos que serão trabalhados no Ensino Fundamental. (BRASIL, 2009c, p. 22). 
Reafirma-se, pois, a importância de a criança viver essa transição sem traumas, pois ambas as etapas da educação básica envolvem saberes, valores e aprendizados, e ambas lidam com o mesmo sujeito: a criança. Assim, cada uma precisa empenhar-se em cumprir seus objetivos e proporcionar a esse sujeito experiências significativas.

Sobre criança, o documento aponta para o entendimento de que ela é:

Sujeito histórico e de direitos que, nas interações, relações e práticas cotidianas que vivencia, constrói sua identidade pessoal e coletiva, brinca, imagina, fantasia, deseja, aprende, observa, experimenta, narra, questiona e constrói sentidos sobre a natureza e a sociedade, produzindo cultura. (BRASIL, 2009c, p. 12).

Tal conceito dialoga com nossa compreensão de criança. No documento, porém, faltam elementos que norteiem o trabalho com essa criança. Afirmamos, mais uma vez, que, apesar de o significado da palavra "diretriz" estar relacionado a normas e caminhos a serem seguidos, as novas DCNEI não avançam além dos discursos. Não esclarecem ao professor as possíveis práticas que levarão à materialização do que é definido no documento nas instituições de educação infantil, especialmente a respeito da apropriação da cultura escrita.

Ainda em 2009, é aprovada a Emenda Constitucional n. 59, que torna a educação básica obrigatória e gratuita dos quatro aos dezessete anos de idade, tornando obrigatório o nível final da educação infantil.

Acreditamos que a apropriação da cultura escrita deva ocorrer de forma significativa a partir de vivências carregadas de significados e funções sociais.

\section{CONSIDERAÇÕES FINAIS}

Realizamos o estudo e a análise sobre os documentos legais e oficiais publicados pelo Ministério da Educação a fim de compreender como orientam o trabalho com a cultura escrita na educação infantil e constatamos que nenhum deles indica a alfabetização ou práticas que remetam a tal processo. Em nenhum deles encontramos a determinação de que devamos alfabetizar as crianças na educação infantil; no entanto, em todos os documentos, é notória a ênfase no trabalho com as várias linguagens, entre elas a oral e a escrita, articuladas com as vivências das crianças, com as brincadeiras, com as relações entre iguais e diferentes. 
Portanto, ao concluir o presente artigo, destacamos que a educação infantil tem um rico material de referência/respaldo nos documentos oficiais e legais, como acabamos de apresentar, e a organização curricular para essa etapa da educação básica mostra termos muito que aprender, especialmente sobre os conceitos de criança, infância e educação infantil. O que temos na prática não condiz com o que temos no papel, na teoria, nos documentos.

Assim, defendemos uma educação para nossas crianças pequenas que prime pela qualidade, pela gratuidade e pela ética. Que possamos deixar nossas crianças serem crianças e viverem plenamente sua infância, sem, contudo, deixar de apresentar-Ihe um mundo cercado de conhecimentos culturais, oferecendo sempre uma cultura mais elaborada. Parafraseando Manoel de Barros (2011), que nossos meninos e meninas deixem de carregar na educação infantil letras nas peneiras para carregarem água a vida toda, enchendo o mundo com seus despropósitos na poesia, na música, na dança, na ciência, na arte, na literatura... Formados por nós como cidadãos leitores e produtores de texto.

\section{REFERÊNCIAS}

BARROS, M. Poesia completa. São Paulo: Leya, 2011.

BRASIL. Critérios para um atendimento em creches que respeite os direitos fundamentais das crianças. 6. ed. Brasília: MEC/SEB, 2009a.

. Indicadores da qualidade na educação infantil. Brasília: MEC/SEB, 2009b.

. Diretrizes Curriculares Nacionais para a Educação Infantil. Parecer CNE/CEB n. 20/2009. Brasília: MEC/SEB, 2009c.

. Política de educação infantil no Brasil: relatório de avaliação. Brasília: MEC/SEB; UNESCO, 2009d.

. Emenda Constitucional n. 59. Brasília: MEC/SEB, 2009 e.

. Parâmetros nacionais de qualidade para a educação infantil. Brasília: MEC/SEB, 2006a. V. 1.

. Política Nacional de Educação Infantil: pelo direito das crianças de zero a seis anos à educação. Brasília: MEC/SEB, 2006b.

. Lei n. 11.274, de 6 de fevereiro de 2006. Brasília: MEC/SEB, 2006c.

. Resolução CEB n. 1, de 7 de abril de 1999. Institui as Diretrizes Curriculares

Nacionais para a Educação Infantil. Brasília: MEC, 1999. Disponível em: <http://portal. 
O lugar da cultura escrita nos documentos legais e oficiais da educação infantil: e os meninos e as meninas carregam letras na peneira

mec.gov.br/cne/arquivos/pdf/CEB0199.pdf>. Acesso em: 11 jan. 2015.

. Parecer CNE/CEB n. 22, de 17 de dezembro de 1998a. Brasília: MEC, 1998a. Disponível em: <http://portal.mec.gov.br/dmdocuments/parecer_ceb_22.98.pdf>. Acesso em: 12 jan. 2015.

. Referencial curricular nacional para a educação infantil. Brasília: MEC/SEF, 1998b. V. 1.

. Referencial curricular nacional para a educação infantil. Brasília: MEC/SEF, 1998c. V. 3.

. Lei n. 9.394, de 20 de dezembro de 1996. Estabelece as Diretrizes e Bases da Educação Nacional. 11. ed. Brasília: Câmara dos Deputados, Edições Câmara, 2015.

FARIA, Ana Lúcia Goulart de; PALHARES, Marina Silveira (Org.). Educação infantil pós-LDB: rumos e desafios. 6. ed. Campinas, SP: Autores Associados, 2007.

MELLO, Suely Amaral. Letramento e alfabetização na Educação Infantil, ou melhor, formação da atitude leitora e produtora de textos nas crianças. In: VAZ, Alexandre Fernandez. MOMM, Caroline Machado (Org.). Educação infantil e sociedade: questões contemporâneas. Nova Petrópolis, RS: Nova Harmonia, 2012.

. Infância e humanização: algumas considerações na perspectiva histórico-cultural. Revista Perspectiva, Florianópolis, v. 25, n. 1, p. 83-104, jan./jun. 2007.

TEIXEIRA, Samanta Felisberto. A infância sexuada e generificada nos documentos legais e oficiais vigentes no Brasil. 2014. Dissertação (Mestrado em Educação)- Universidade Federal de Mato Grosso do Sul, Corumbá, MS, 2014.

VIGOTSKI, Lev Semionovich. Quarta aula: a questão do meio na pedologia. Traduzido por Márcia Pileggi Vinha. Psicologia USP, São Paulo, 2010. Disponível em: <http://www.scielo. br/pdf/pusp/v21n4/v21n4a03.pdf>. Acesso em: 12 jan. 2015.

. A brincadeira e o seu papel no desenvolvimento psíquico da criança. Traduzido por Prestes. Revista Virtual de Gestão de Iniciativas Sociais, jun. 2008. Disponível em: <http://www.Itds.ufrj.br/gis/anteriores/rvgis11.pdf>. Acesso em: 12 jan. 2015.

\section{Sobre as autoras:}

Regina Aparecida Marques de Souza: Pós-Doutora pela Universidade de Évora, Portugal e UNESP/Marília, doutora em Educação pela UNICAMP; mestre em Educação pela Universidade Federal de Mato Grosso do Sul (UFMS)/Campo Grande e Pedagoga pela UFMS/Três Lagoas. Professora do curso de Pedagogia da UFMS, campus de Três Lagoas e do programa de Pós-Graduação em Educação, campus do Pantanal. E-mail: reginaamarques@hotmail.com 
Priscila Souza Damazio Piol: Mestre em Educação pela UFMS/Corumbá, especialista em Educação Infantil pela UFMS/Campo Grande e Pedagoga pela UFMS/ Campo Grande. Atua como coordenadora pedagógica em um Centro de Educação Infantil em Campo Grande, MS. E-mail: pri_damazio@hotmail.com

Recebido em março de 2018

Aprovado em maio de 2018 